\title{
Seeing Leadership More Clearly Through the Lens of Diversity and Inclusion
}

\author{
William Lee McClain \\ University of Phoenix \\ Stacey Rene' Vande Linde \\ George Washington University
}

Despite federal laws prohibiting discrimination related to diversity and inclusion (D\&I) in the workplace, organizations continue to struggle with enforcing this mandate. This article examines how leaders who are innovative and bold in their attention to D\&I will see leadership more clearly through the lens of D\&I. The authors examine four innovative D\&I steps: establish D\&I position as a new member of the C-suite, link $C$-suite salary and bonus with D\&I objectives, open a wider aperture with D\&I instruction in K-12, and create your own D\&I game-changing narrative. The authors conclude with probing questions that call for leaders to be innovative when addressing $D \& I$.

Keywords: diversity and inclusion, leadership, leaders and innovative

\section{INTRODUCTION}

The work-setting landscape has evolved in response to societal changes globally. The mix of unique people, whose uniqueness endures, demands that everyone's voice is heard despite their different perspectives. In the work environment, companies increasingly rely on leaders to manage diversity and inclusion (D\&I) with fairness. Despite the current body of work on (D\&I), no "one-size-fits-all" universal theory can help in confronting the high winds and waters that leaders must navigate to achieve success. Thus, we argue that when organizations and leaders are innovative and bold in their attention to diversity and inclusion, the optics of leadership are clear and focused, and leaders are poised for sustainable success.

Imagine a hot Tuesday afternoon in the year 2030. Pope William McClain III, a Korean American who took his name in honor of history's first Korean Pope, is at center stage. The Pope is forthright in his assertion that he is the shepherd of the universal Church, not just a son of Korea. Instead of the gentle papal wave of his predecessors, McClain pumps both of his fists and yells, "Diversity now, diversity tomorrow, diversity forever!" As the Pope exits, he holds to form, and the crowd acknowledges several of his jokes. Journalists are hoping for comments from the Pope on the recent appalling diversity practices by leaders around the world. Today, however, the Pope decides not to talk about specific leaders and bad diversity practices; instead, he talks about the future of our world in terms of embracing diversity and inclusion as the bridges to equality.

The foregoing may seem like a scene from a papal potboiler. Nevertheless, the Pope's actions and focus on embracing diversity and inclusion are firmly grounded in expected trajectories for the world over the next 20-30 years. Therefore, while the details are fiction, the story stands in the realm of reality. Do 
innovative and bold attention to diversity and inclusion practices really need examination for the optics of leadership to be clear and focused? Follow the narrative and you can judge for yourself.

\section{ACCOUNTABILITY BEYOND METRICS}

"Isn't it amazing that we are all made in God's image, and yet there is so much diversity among His people?" -Desmond Tutu

The many diversity tools for keeping organizations and leaders on track constitute an endless list, but the need to be innovative and bold throughout the process is an essential element that is often overlooked. For example, consider metrics in the form of a D\&I scorecard of objectives. While numbers do not lie and objectives are a good roadmap, where is the innovative and bold approach to opening the aperture for diversity and inclusion to flourish? Throughout, this article specifically refers to D\&I. On the surface, most large organizations pay ample attention to the element of diversity but exclude the icing on the cake, inclusion. The result is no cross-pollination of innovation and creativity in a diverse setting. Frost (2018), an expert in the field of diversity and inclusion, paints a picture of inclusion as the necessary link for quality decision-making, understanding the point of needing and retaining customers and opening the door to challenging good ideas with better ideas (p. 124). The best modern example of this is Michael Jordan, who retired from professional basketball in 2003 but whose Air Nike basketball sneakers remain the best-selling basketball sneakers worldwide. On the surface, the distinction of the greatest basketball player of all time draws buyers who were not alive during the time he played professional basketball (White, 2019). However, the actual reason for the Air Jordan brand being the best-sellers for over 36 years is an inclusive feeling around the game of basketball for those who play or are fascinated with the game. Diversity alignment within society requires that we live, lead, integrate, and accommodate to make organizations moreinclusive with innovation-this will require establishing a D\&I position as a new member of the C-suite (Frost, 2018, p. 124).

\section{Innovative D\&I Step \# 1: Establish D\&I Position as a New Member of the C-Suite}

The first innovative and bold step toward accountability is identifying the senior Diversity Executive Officer as a new, permanent member of the C-suite and detaching D\&I from Human Resources (HR). In some organizations, the senior Human Resources Executive is responsible for diversity, talent acquisition, and human capital. It is neither surprising nor disturbing that diversity programs do not generate the desired results. The dated organizational structure does not reflect that while D\&I shares common elements with HR functions, D\&I needs more room to operate freely for cross-functional pollination and sustainable results (Shi, W. et al., 2018, p. 84).

\section{Innovative D\&I Step \# 2: Link C-Suite Salary and Bonus With D\&I Objectives}

If selecting the right $\mathrm{C}$-suite team is important, then companies should align their D\&I success to Csuite compensation. The next innovative and bold step is to link the $\mathrm{C}$-suite salaries and bonuses with D\&I objectives. For example, collegiate and professional coaches, such as Tom Izzo, head basketball coach for the Michigan State Spartans, have salaries and bonuses linked to their performance. In 2020, Izzo's base salary was over 4 million. If he leads his team to specific performance benchmarks, Izzo will earn over $\$ 600,000$ as a bonus (Solari, 2020). The same approach to connecting C-suite salaries and bonuses to D\&I objectives is logical and necessary right now. Several large companies have voluntarily linked their CEO's salary and bonus to D\&I objectives. For example, research conducted by Forbes Coaches Council depicts steps that Expedia has taken to vastly value diversity by tying executive compensation to diversity goals (Forbes Coaches Council,2018).D\&I's intrinsic worth should be aggressively pursued through an unbiased process, with accountability.

On the surface, hiring leaders to fill C-suite positions focuses much attention on the body of work. However, to enhance future leaders at all levels, society must establish diversity and inclusion education as the norm for children's ways of thinking, into adulthood. 


\section{ENTERPRISE DIVERSITY AND INCLUSION EFFORTS}

"So long as you remain blindly obedient to your own culture, other cultures would always remain as 'other' cultures." - Abhijit Naskar

What does it take to become a leader who is grounded and intelligent in diversity principles? A big heart? An effective leadership approach? A good mentor? A good teacher? A good coach? If that is what you believe, then think again. Recent research conducted by Jones (2019), a thought leader in human-capital management, states that "only 27 percent of HR organizations require employees to engage in diversity and inclusion training" (p. 39). The importance of this article is its emphasis on how education, beginning with K-12 and supported and improved upon in the work setting, drives leaders and organizations to embrace and champion D\&I as an enterprise. Influencing the value of D\&I through the lens of cultural diversity is crucial to producing D\&I muscle memory for future leaders at an earlier age. As a matter of fact, in the article Mapping Cultural Diversity Through Children's Voices: From Confusion to Clear Understandings, authors Hajisoteriou, Karousiou, and Angelides (2017) examine the element of friendship with immigrant and native students, aged 11 to 12, at five primary schools. The findings suggest that friendship between immigrant and native students could offset their lack of cultural awareness and inclusion (p. 330). Despite the landscape, the instinct to draw back to the cultural awareness and inclusion rooted in an unbiased setting during childhood is valuable for all leaders in general, and for CEOs, when applying emotional intelligence. However, ensuring that the optics of leadership among future leaders is clear and focused on diversity and inclusion requires a wider aperture, with D\&I instruction in the K-12 curriculum.

\section{Innovative D\&I Step \# 3: Open a Wider Aperture With D\&I Instruction in K-12}

Wisely advocating for a wider net with D\&I instruction early in K-12 includes providing some level setting and context for how the mindset on diversity and inclusion among today's leaders links to their belief about whether leaders are born or made. Recently, the Center for Creative Leadership conducted a study of 361 senior executives from the U.S., Australia, South Africa, India, and the UK finding that " 19.1 percent believed that leaders are born, 28.5 percent believed that leaders are equally born and made, and 52.4 percent believed that leaders are made" (Gentry et al., 2012, p. 6). On the surface, the numerous examples of military leaders who were born include Audie Murphy, a decorated World War II hero who was promoted from Private to 2nd Lieutenant for his leadership actions on the battlefield. Murphy accomplished many heroic acts with no formal military training as a noncommissioned or commissioned officer (Conger, 1977). However, that example is the exception, not the norm.

When we dig deeper, we find a strong concern emerges about the perception that leaders are bom. If that perception plays out in recruitment, promotion, and specifically managing D\&I, then will the organization focus on born leaders or include talent from a wider pool? No doubt, leaders are shaped by their experience and education. However, what is the connection with D\&I instruction in K-12? Experts in the field of culture and diversity contend thatK-12 students who are intellectually immersed and challenged with culturally relevant texts experience a sharp change in their knowledge, skills, and attitudes directly connected to their growth and understanding of D\&I in both the academic setting and the workplace. Sharma and Christ (2017), experts in K-12 education, offer five simple, innovative steps to help K-12 teachers implement culturally relevant text selection and integration in their curriculum:

- Recognize the need for culturally responsive instruction;

- Get to know more about your students' lives;

- Search for culturally relevant texts;

- Select culturally relevant texts for instruction;

- Identify critical and personal-response opportunities for instruction (p. 295).

While seeking culturally relevant texts in K-12 is a good step in the right direction, capturing the less available students and creating a D\&I enterprise in academic settings and the workplace requires making D\&I a core subject for K-12 and teachers proficiently trained on the topic. This is bold and innovative! 
Concurrently, D\&I strategy and change management must be aligned and not separate matters in order to ensure that everyone has a seat at the big table where their input is valued.

\section{Innovation Comes From Change—Not Yesterday's Success}

"The price of doing the same old thing is far higher than the price of change." - Bill Clinton

Many factors contribute to the need for change management as it relates to D\&I. No different than any other specific change management situation, this one requires attention to balancing and syncing systems, processes, and people in order to achieve the best results. Given the high stakes, determining who should lead change management as it relates to D\&I is vital. The answer should be plural and the weight of this effort should not rest solely on the shoulders of the executive D\&I officer. For the Department of Defense (DoD) to stay relevant, change is a necessity, but it is often viewed as something everyone else must do to improve. This is where D\&I is both critical and challenging to the culture of an organization as it is for the DoD. Oddly, on its face, DoD has embedded D\&I within its foundation to ensure that our nation deters and wins wars. This requires different services and organizations within a service, proud of its history and tradition, coupled with a rank-structuretype of service (civilian, contractor, or uniform) as well as education and various socioeconomic backgrounds, races, genders, ages, and ethnicities. The DoD plays to these strengths in times of crisis because success and the lives of men and women beside them in battle and their families/friends at home are at stake. There is a sense of unfathomable consequence to failure so they come together and leverage the resident diversity to solve the immediate threat. The D\&I story can be a powerful tool in shaping D\&I initiatives. It begins with creating your own D\&I game-changing narrative.

\section{Innovative D\&I Step \# 4: Create Your Own D\& I Game-Changing Narrative}

Hardly a conversation or a meeting happens without a change requirement. The best narrative requires creativity, the province of the right side of your brain. For example, when Texas Commerce Bank was $\$ 50$ million overspent, the leader did not fire any employees; instead, they changed the narrative of what the future could hold for everyone: a thriving business and continued employment for a diverse workforce (Katzenbach, 1995). This occurred in the 1990s, but today's leaders can create their own D\&I gamechanging narrative with the same or better outcomes. The saying "don't bring a knife to a gunfight" fittingly describes the firepower a leader needs to be a D\&I game-changer for his or her organization. What empowers a leader to create his or her own D\&I game-changing narrative? First is the right mindset. Other playmakers may have more education, aptitude, and experience, but a game-changer's mindset is not confined to a process; rather, it is a new journey that is different and imaginative, beyond operating inside a box. The second is risk management. How does a game-changer approach risk? You must be ready to take both small and large risks with 100 percent certainty. It's just leadership, both the art and the science.

\section{CONCLUSION}

When organizations and leaders are innovative and bold in their attention to diversity and inclusion, the optics of leadership are clear and focused, and the organization is poised for sustainable success. Without a doubt, striving for diversity in its raw form is not always fair and the process is broken at times. But the question for all leaders is: "Do you care enough to improve or create a new process and stand up for diversity?" The writing is on the wall! The workplace is being transformed and all leaders must be stewards of D\&I in their organizations. This journey begins and ends with leaders following the four innovative D\&I steps explained in this article. Leaders must convey a compelling message to support and commit to diversity and inclusion now. This is where the rubber meets the road. 


\section{REFERENCES}

Conger, R. (1977). Audie Murphy, American soldier Harold B. Simpson. The Southwestern Historical Quarterly, 81(2), 242.

Forbes Coaches Council. (2018, August 13). Practice what you preach: How any organization can truly embrace diversity. Forbes. Retrieved from https://www.forbes.com/sites/forbescoachescouncil/2018/08/13/practice-what-you-preach-howany-organization-can-truly-embrace-diversity/\#3420da1152c3

Frost, S. (2018). How diversity (that is included) can fuel innovation and engagement - and how sameness can be lethal. Strategic HR Review, 17(3), 119-125.

Gentry, W., Deal, J.J., Stawiski, S., \& Ruderman, M. (2012). Are leaders born or made? Center for Creative Leadership. Retrieved from https://www.ccl.org/wpcontent/uploads/2015/02/AreLeadersBornOrMade.pdf

Hajisoteriou, C., Karousiou, C., \& Angelides, P. (2017). Mapping cultural diversity through children's voices: From confusion to clear understandings. British Educational Research Journal, 43(2), $330-349$.

Jones, K. (2019). The numbers game and what it means for diversity \& inclusion (D\&I). Workforce Solutions Review, 10(2), 38-40.

Katzenbach, J.R.(1995). Real change leaders: How you can create growth and high performance at your company. Time Business.

Sharma, S.A., \& Christ, T. (2017). Five steps toward successful culturally relevant text selection and integration. Reading Teacher, 71(3), 295-307.

Shi, W., Pathak, S., Song, L.J., \& Hoskisson, R.E. (2018). The adoption of chief diversity officers among S\&P 500 firms: Institutional, resource dependence, and upper echelons accounts. Human Resource Management, 57(1), 83-96.

Solari, C. (2020, January 16). Michigan State basketball coach Tom Izzo to receive one-time, \$4 million bonus in 2022. USA Today. Retrieved from https://www.usatoday.com/story/sports/ncaab/bigten/2020/01/16/michigan-state-basketball-tomizzo-retention-bonus-2022/4487146002/

White, R.W. (2019, February 19). How Michael Jordan became a brand (even though he almost skipped the meeting with Nike). The Seattle Times. Retrieved from https://www.seattletimes.com/business/how-michael-jordan-became-a-brand-even-though-healmost-skipped-the-meeting-with-nike/ 